\title{
Structure activity relationship (SAR) and quantitative structure activity relationship (QSAR) studies showed plant flavonoids as potential inhibitors of dengue NS2B-NS3 protease
}

\author{
Muhammad Waseem Sarwar ${ }^{1}$, Adeel Riaz' ${ }^{1}$ Syed Muhammad Raihan Dilshad ${ }^{5}$, Ahmed Al-Qahtani ${ }^{2,3,4}$,
} Muhammad Shah Nawaz-UI-Rehman ${ }^{1}$ and Muhammad Mubin ${ }^{{ }^{*}}$

\begin{abstract}
Background: Due to dengue virus disease, half of the world population is at severe health risk. Viral encoded NS2B-NS3 protease complex causes cleavage in the nonstructural region of the viral polyprotein. The cleavage is essentially required for fully functional viral protein. It has already been reported that if function of NS2B-NS3 complex is disrupted, viral replication is inhibited. Therefore, the NS2B-NS3 is a well-characterized target for designing antiviral drug.

Results: In this study docking analysis was performed with active site of dengue NS2B-NS3 protein with selected plant flavonoids. More than 100 flavonoids were used for docking analysis. On the basis of docking results 10 flavonoids might be considered as the best inhibitors of NS2B-NS3 protein. The interaction studies showed resilient interactions between ligand and receptor atoms. Furthermore, QSAR and SAR studies were conducted on the basis of NS2B-NS3 protease complex docking results. The value of correlation coefficient $(r) 0.95$ shows that there was a good correlation between flavonoid structures and selected properties.
\end{abstract}

Conclusion: We hereby suggest that plant flavonoids could be used as potent inhibitors of dengue NS2B-NS3 protein and can be used as antiviral agents against dengue virus. Out of more than hundred plant flavonoids, ten flavonoid structures are presented in this study. On the basis of best docking results, QSAR and SAR studies were performed. These flavonoids can directly work as anti-dengue drug or with little modifications in their structures.

Keywords: Flavonoids, QSAR, SAR, Molecular docking, Dengue virus, NS2B-NS3

\section{Background}

Dengue virus belonging to family Flaviviridae is the most prevalent arthropod transmitted virus in humans. It can cause symptoms ranging from self-limiting dengue fever to sometimes-fatal dengue hemorrhagic fever [1].

Dengue virus is a positive sense single stranded ssRNA virus with $10.7 \mathrm{~kb}$ genome. Viral RNA is translated into a single polyprotein. The poly protein is cleaved by virus

\footnotetext{
* Correspondence: mmubin@uaf.edu.pk

'Virology Lab, Centre of Agricultural Biochemistry and Biotechnology,

University of Agriculture, Jail road, Faisalabad 38000, Pakistan

Full list of author information is available at the end of the article
}

encoded NS2B/NS3 protease and the host proteases into structural proteins $\mathrm{C}, \mathrm{M}$, and $\mathrm{E}$ as well as nonstructural proteins NS1, NS2A, NS2B, NS3, NS4A, NS4B, and NS5 to initiate the replication of dengue virus $[2,3]$.

The NS2B-NS3 protease contains two functional regions i.e., a C-terminal region acting as RNA helicase and a $\mathrm{N}$-terminal 180-residue is a trypsin like serine protease (Fig. 1). NS3 protease requires the central hydrophilic region of NS2B (NS2B; residues 49 to 95) to perform proteolytic activity and to stabilize folding. Thus, hydrophilic domain of NS2B interacts with NS3 protease and forms full active site [4]. The activity of

(c) The Author(s). 2018 Open Access This article is distributed under the terms of the Creative Commons Attribution 4.0 International License (http://creativecommons.org/licenses/by/4.0/), which permits unrestricted use, distribution, and 


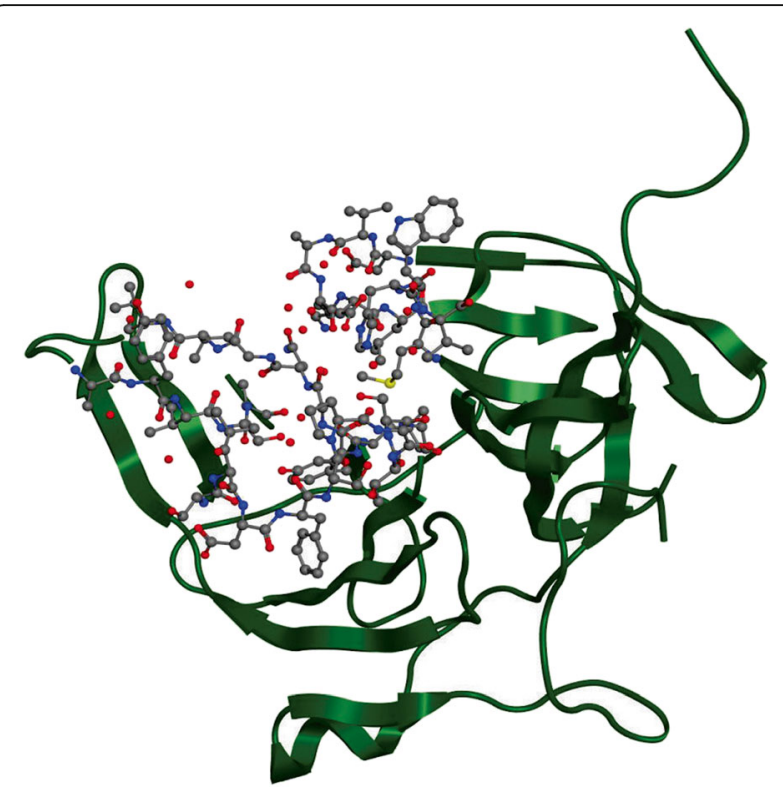

Fig. 1 Structure of dengue NS2B-NS3 (2FOM); Catalytic site is shown in ball stick model

NS2B/NS3 is critical for viral replication [5] as the disruption of NS2B-NS3 function inhibits viral replication [6-8]. So NS2B/NS3 protease could be targeted for the development of anti-DENV inhibitors.

Plants had served as a source of medicinal compounds for a long time and are basis of many pharmaceuticals now days [9]. Flavonoids are plant based phenolic compounds [10] having various biological properties like antiviral [11, 12], antioxidant, antifungal [13], anti-cancerous [14, 15], anti-angiogenic [16] and anti-inflammatory properties $[17,18]$.

Henceforth, flavonoids may act as inhibitors of dengue NS2B-NS3. In this study, in-silico screening using automated docking method was performed and binding models of dengue NS2B-NS3 protease with selected plant flavonoids are proposed. Finally, ten plant flavonoids were suggested as potential inhibitors of dengue virus NS2B-NS3 complex. Furthermore extensive studies of binding modes were performed using SAR model i.e., (Structure Activity Relationship) and QSAR model i.e., (Quantity Structure Activity Relationship) [19]. This study provides the novel insights in the development of anti-viral drugs against dengue virus.

\section{Methods}

All analyses presented here were performed using 64-bit Operating System and Intel(R) Core(TM) i5-5200 U processor with $2.2 \mathrm{GHz}$ processing speed. MOE (Molecular Operating Environment) software was used for computational analysis, provided by chemical computing group Inc. and Chimera software was used for protein structure manipulation.

\section{Preparation of receptor structure}

Crystal structure of NS3-NS2B protease was obtained from Protein Data Bank (http://www.rcsb.org) with PDB ID 2FOM [20]. The protein consists of two chains and 185 residues length with resolution $1.5 \AA$. The ribbon diagram of target structure with catalytic site is shown in Fig. 1. This structure was subjected to 3D protonation and energy minimization using parameters like (gradient: 0.05, Force Field: MMFF94X + Solvation) using MOE Program. For docking the minimized structure was used as the receptor protein [21].

\section{Ligand preparation}

More than 100 chemical structures of ligand flavonoid molecules were downloaded online from chebi (http:// www.ebi.ac.uk/chebi/) in .mol format. These structures were prepared for docking in LigX module of MOE program with parameters (gradient: 0.05, Force Field: MMFF94X).

\section{Docking setup and run}

The binding sites for the target protein were calculated, for docking analysis, by MOE site finder and then confirmed with the binding site reported in literature. During docking setup, only this binding site (His51, Asp75 and Ser135) was used (Fig. 1) to find the correct conformation of the ligand. To bind the selected ligands with receptor protein, MOE docking program with default parameters was used. MOE London dG scoring function was used to estimate free energy of binding for each ligand from a given pose [22]. The functional form of London dG scoring function is a sum of terms:

$$
\begin{aligned}
\Delta G= & c+E_{f l e x}+\sum_{h \text {-bonds }} c_{H B} f_{H B}+\sum_{m-\text { lig }} c_{M} f_{M} \\
& +\sum_{\text {atoms } i} \Delta D_{i}
\end{aligned}
$$

The difference in desolvation energies is calculated according to the formula [23].

$$
\Delta D_{i}=c_{i} R_{i}^{3}\left\{\iiint_{u \notin A \cup B}|u|^{-6} d u-\iiint_{u \notin B}|u|^{-6} d u\right\}
$$

The final docking output was saved for further investigations.

\section{Ligand interactions studies}

The ligand interactions were studied by Ligand Interaction module in MOE Program. It includes 2D and 3D representations of ligand and receptor protein interactions and 
calculated distances among ligand and protein interacting atoms.

\section{Calculation of descriptors}

Descriptor refers to the two-dimensional (2-D) or threedimensional (3-D) physiochemical property of a molecule [23]. The descriptors that were calculated in this study are as follows. $\log \mathrm{P}(\mathrm{o} / \mathrm{w})$ is the logarithm of the octanol and water partition coefficient. b_count is the number of bonds (including implicit hydrogens). This is calculated by the addition of $(\mathrm{di} / 2+\mathrm{hi})$ over all nontrivial atoms i. b-rotN is the number of rotatable bonds. With order 1, having at least two heavy neighbors and provided it is not in a ring, a bond is said to be rotatable. chi1 is the atomic connectivity index. a_acc is the number of hydrogen bonds of acceptor atoms (not counting acidic atoms but counting atoms that are both hydrogen bond donors and acceptors such as - $-\mathrm{OH})$. Q_pc + is the total positive partial charge i.e., the sum of the positive qi. Q_PC+ is identical to PC+ that has been reserved for compatibility. Q_pc-PC is the total negative partial charge and it is the sum of the all negative qi. SlogP is the logarithm of the octanol and water partition coefficient (including hydrogens). Log $\mathrm{S}$ is the logarithm of the aqueous solubility $(\mathrm{mol} / \mathrm{L})$. apol is the sum of the atomic polarizabilities. a_don is the number of hydrogen bond acceptor atoms. vsurf_g is the surface globularity. vsurf_wpu is the Hydrophilic volume. $\mathrm{E}$ is the value of the potential energy. E_ele is the electrostatic component of the potential energy. E_nb is the value of the potential energy with all bonded positions that have been disabled.

\section{Studies about structure activity relationship (SAR) and quantitative structure activity relationship (QSAR)}

The Structure-Activity Relationship (SAR) report was generated by MOE application to find common scaffolds in flavonoid structures used in this study. The input data was flavonoid structures in .mol file format. StructureActivity Report involves gathering of input data (molecules, activity, predefined scaffolds, etc.) and detection of common scaffolds. After that, Alignment of the scaffolds was done to produce a common numbering system by using ligand alignment module of MOE program.

The Quantitative Structure Activity Relationship (QSAR) was done in MOE. All docked molecules were used for training set. In a test set, QSAR model correlates the activities with properties inherent to each molecule. Different molecular descriptors were used to evaluate these properties. QSAR studies involve two steps. In first step, descriptors were generated that encode chemical structure information. During second step, a statistical regression technique is employed to correlate the structural variation, as encoded by the descriptors, with the variation in the biological activity of protein. To test the reliability of results, regression analysis was performed using inhibitory activity as dependent variable and the descriptor as predictor variables. After making sure the reasonable correlation of inhibitory activity with the individual descriptor, QSAR models were derived The predictor variables with $p$ value greater than 0.05 were eliminated while obtaining the QSAR models, to assure their statistical reliability.

\section{Results}

\section{Docking analysis}

Docking of all flavonoid structures (Fig. 2) was done against the active site of dengue NS2B-NS3 protein. Docking analysis provided a number of configurations that were scored to determine favorable binding modes. The flavonoid structures with high docking scores with molecular data are summarized in Table 1.

\section{Calculation of ligand interaction}

Ligand interactions were obtained by MOE program. The Ligand Interactions studies are used to visualize an active site of a complex in diagrammatic form. Depicted view of $3 \mathrm{D}$ interaction is shown in Fig. 3. Flavonoid 1 formed an interaction with three amino acids of viral protein (Gly 87, Val 146 and Asn 167) with in the active site (Fig. 4a). Flavonid 2 formed the interaction with two amino acids of viral protein (Lys 74 and Ile 165) with in active site (Fig. 4b). Flavonoid 3 formed an arene-arene link with amino acid Trp 83 (Fig. 4c). Flavonoid 4 formed interaction with three amino acids (Trp 83 Gly 87 and Val 146) (Fig. 5a). Flavonoid 5 formed an arene cationic link with amino acid Lys 74 (Fig. 5b). Flavonoid 6 formed the interaction with Lys 74 (Fig. 5c). Flavonoid 7 interacted as a cationic arene interaction with Lys 74 and a hydrogen bond donation with Trp 83 (Fig. 6a). Flavonoid 8 formed interaction with Asn 167, Val 147 and Trp 89 (Fig. 6b). Flavonoid 9 has shown an interaction with amino acid Gly 87 and Trp 83 (Fig. 6c). Flavonoid 10 formed a cationic arene link with Lys 74 and an hydrogen bond with Trp 83 (Fig. 6d).

\section{Structure activity report}

The Structure-Activity Report is a MOE application, which generates a web page housing an interactive view onto a collection of molecules, which are related by a small number of related common scaffolds. The application is designed to operate on small databases of druglike molecules, which are in the process of being refined for improved binding affinity and other pharmacological properties. Report was generated using a panel from an interactive session of MOE, using a MOE molecular database. The default browser was launched to show the results, when the generation was completed. 
<smiles>C[C@@H]1O[C@@H](Oc2c(-c3ccc(O)c(O)c3)oc3cc(O)cc(O)c3c2=O)[C@H](O[C@]2(O)O[C@H](COC(=O)/C=C/c3ccc(O)c(O)c3)[C@@H](O)[C@H](O)[C@H]2O)[C@@H](O)[C@H](O)[C@@H]1O</smiles><smiles>O=c1c(O)c(-c2cc(O)c(O)c(O)c2)oc2cc(O)cc(O)c12</smiles><smiles>C[C@@H]1O[C@H](OC[C@H]2O[C@H](Oc3cc(O)c4c(c3)O[C@@H](c3ccc(O)c(O)c3)CC4=O)[C@H](O)[C@H](O)[C@@H]2O)[C@H](O)[C@@H](O)[C@@H]1O</smiles><smiles>[Y]C[C@H]1c2cc(O)c(O)cc2Oc2cc(O)c3c(c21)O[C@H](c1ccc(O)c(O)c1)[C@H](O)C3</smiles><smiles>[B]O[C@H]1O[C@H](CO[C@H]2O[C@H](CO)[C@@H](O)[C@H]2O)[C@@H](O)[C@H](O)[C@H]1Oc1cc(O)c2c(=O)c(OC)c(-c3ccc(O)cc3)oc2c1</smiles><smiles>COc1c(O[C@@H]2O[C@H](C(=O)O)[C@@H](O)[C@H](O)[C@H]2O)cc(O)c2c(=O)cc(-c3ccccc3)oc12</smiles><smiles>COc1cc([C@]2(C)Oc3c(O)cc([C@@H]4Oc5cc(O)cc(O)c5C(=O)[C@H]4O)cc3[C@H]2O)ccc1O</smiles>

Fig. 2 Flavonoid structures that shown best results of docking analysis; 1. quercetin 3-O-(2",3"-digalloyl)-- 3 -D-galactopyranoside 2. quercetin 3-O-a(6"'-caffeoylglucosyl- $\beta$-1,2-rhamnoside) 3. schaftoside 4. myricetin 5. quercetin 3-sulfate 6. eriocitrin 7. catiguanin B 8. 4,5,7-trihydroxy-3-methoxyflavone-7-0a-L-arabinofuranosyl $(1 \rightarrow 6)-\beta$-D-glucopyranoside 9 . wogonin 7-O- $\beta$-D-glucuronide 10. silychristin 
Table 1 Selected flavonoid molecules downloaded from chebi (http://www.ebi.ac.uk/chebi/), shown higher docking score

\begin{tabular}{|c|c|c|c|c|}
\hline Flavonoid No. & Chebi ID & Name & Plant Sources & $\begin{array}{l}\text { Docking Score } \\
\text { (Kcal/mol) }\end{array}$ \\
\hline 1 & 66,287 & quercetin 3-O-(2",3"-digalloyl)- $\beta$-D-galactopyranoside & Euphorbia lunulata & -26.101 \\
\hline 2 & 66,284 & quercetin 3-O-a-(6"'-caffeoylglucosyl- $\beta$-1,2-rhamnoside) & Sedum sarmentosum & -24.987 \\
\hline 3 & 9047 & schaftoside & Passiflora tripartita & -23.399 \\
\hline 4 & 18,152 & myricetin & Myrica rubra & -21.987 \\
\hline 5 & 17,730 & quercetin 3-sulfate & Anethum graveolens & -20.989 \\
\hline \multirow[t]{2}{*}{6} & \multirow[t]{2}{*}{28,709} & \multirow[t]{2}{*}{ eriocitrin } & Citrus lumia & \multirow[t]{2}{*}{-20.693} \\
\hline & & & Cyclopia subternata & \\
\hline 7 & 65,602 & catiguanin B & Trichilia catigua & -20.414 \\
\hline 8 & 68,348 & $\begin{array}{l}\text { 4,5,7-trihydroxy-3-methoxyflavone-7-O-a-L-arabinofuranosyl } \\
(1 \rightarrow 6) \text { - } \beta \text {-D-glucopyranoside }\end{array}$ & Lepisorus contortus & -20.378 \\
\hline 9 & 61,282 & wogonin 7-O- $\beta$-D-glucuronide & Scutellaria baicalensis & -20.102 \\
\hline 10 & 9143 & silychristin & Silybum marianum & -20.085 \\
\hline
\end{tabular}

Scaffold categorization needs a small number of common scaffolds for best results. Alignment of the scaffolds was done to produce a common numbering system by using ligand alignment module of MOE program. One common scaffold was obtained from the alignment of all ten flavonoid structures (Fig. 7). These results show that there is a prevalence of similarity among the structural formulas of different flavonoid compounds performing the same function i.e. binding with active site of NS3-NSB protein of dengue virus.

\section{QSAR model}

The biochemical activities in this work were analyzed for cross correlation of activities and chemical descriptors to find out whether for observed inhibitory effect against NS2B-NS3 complex is there any common structure activity relationship. It was discovered that there was a high level of correlation between the observed parameters with a correlation coefficient $(\mathrm{r})$ of value 0.956 . So to clarify conceivable QSARs for each compound with its biological activity, atomic models of flavonoids were constructed. The structures of flavonoid compounds were shown in Fig. 2 and data was presented in Table 1. These flavonoids modeled keeping in view the patterns of hydrogen bonding and hydrophobic interactions and the induced fit phenomena that best express the binding affinity of each structure as accessed from $\log \mathrm{P}$ values. These $\log \mathrm{P}$ were separated as training set and test set values. Since there was no pervious information of flavonoid inhibition of dengue NS2B-NS3 complex available, 10 flavonoids showing best docking results were used for both training set as well as test set. The values of test set were approximately the same as that for training set (Fig. 8) clearly showing that there is a positive correlation between the values of $\log \mathrm{P}$ and activities. The parameters used in QSAR model

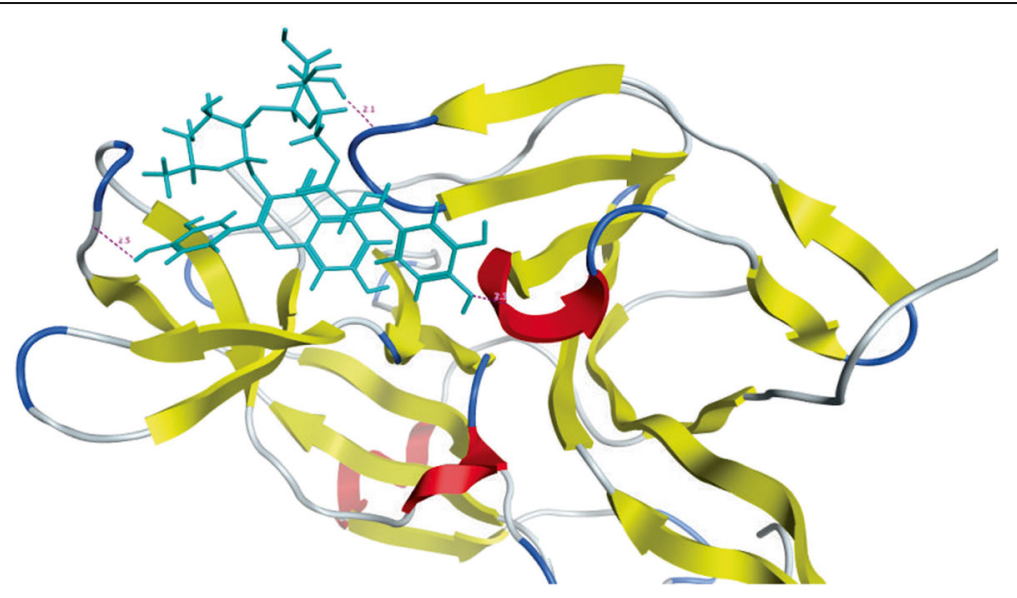

Fig. 3 3D interaction diagram; Dotted lines showing the interactions between ligand and receptor protein atoms with calculated distances 


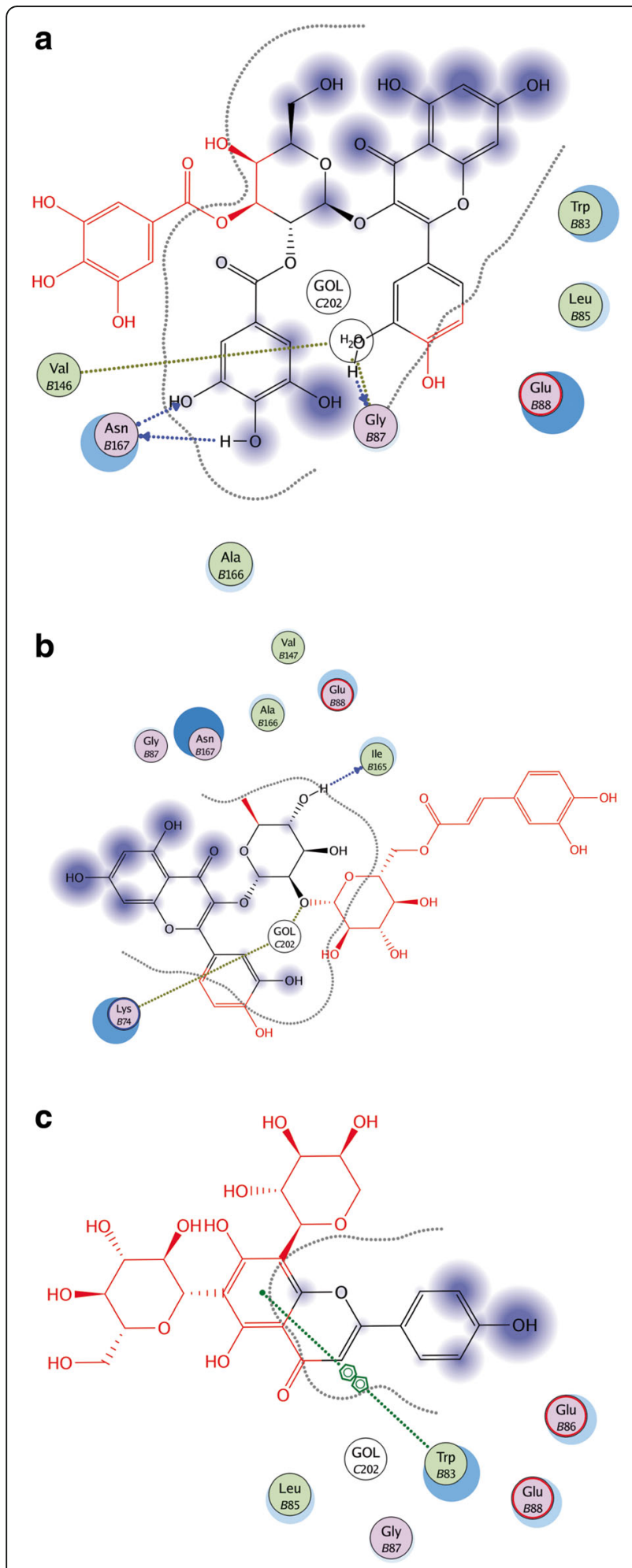

Fig. 4 2D interaction diagram; showing the interacting ligand atoms with specific residues in receptor protein. Dotted lines are showing specific interaction. a. Flavonoid No.1 b. Flavonoid No. 2 c. Flavonoid No. 3 a

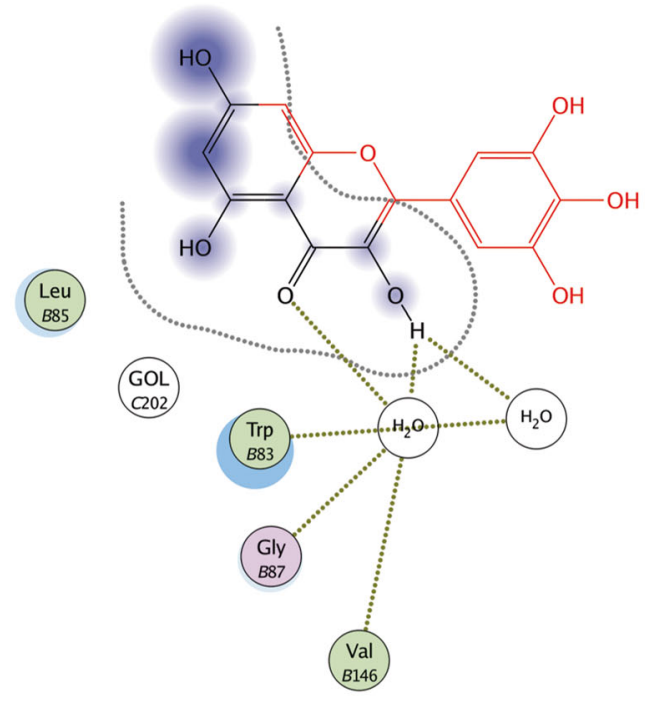

b Ala

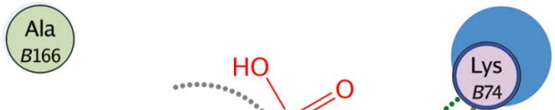

Ile
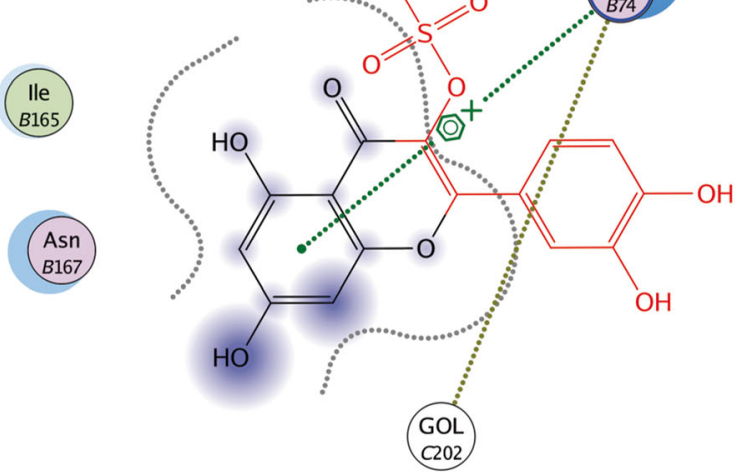

C

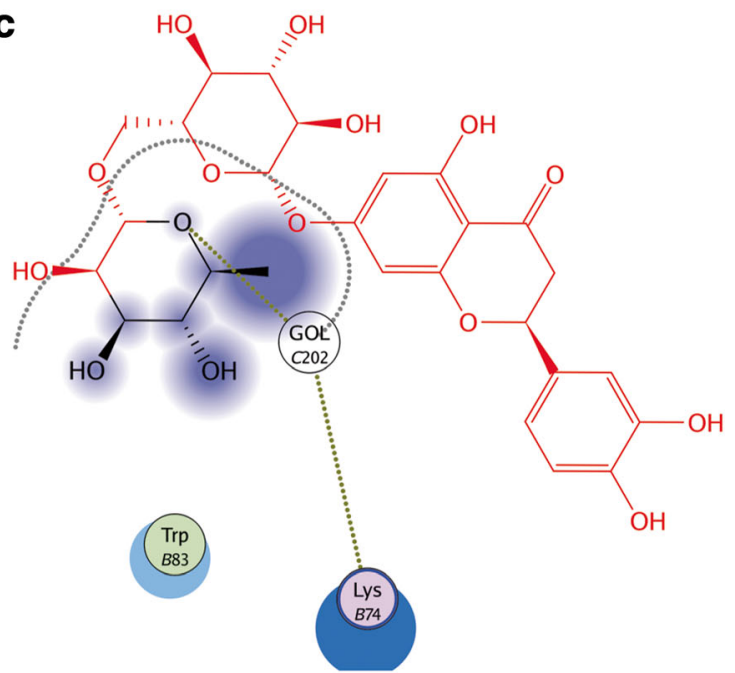

Fig. $52 \mathrm{D}$ interaction diagram; showing the interacting ligand atoms with specific residues in receptor protein. Dotted lines are showing specific interaction. a. Flavonoid No. 4 b. Flavonoid No. 5 c. Flavonoid No. 6 


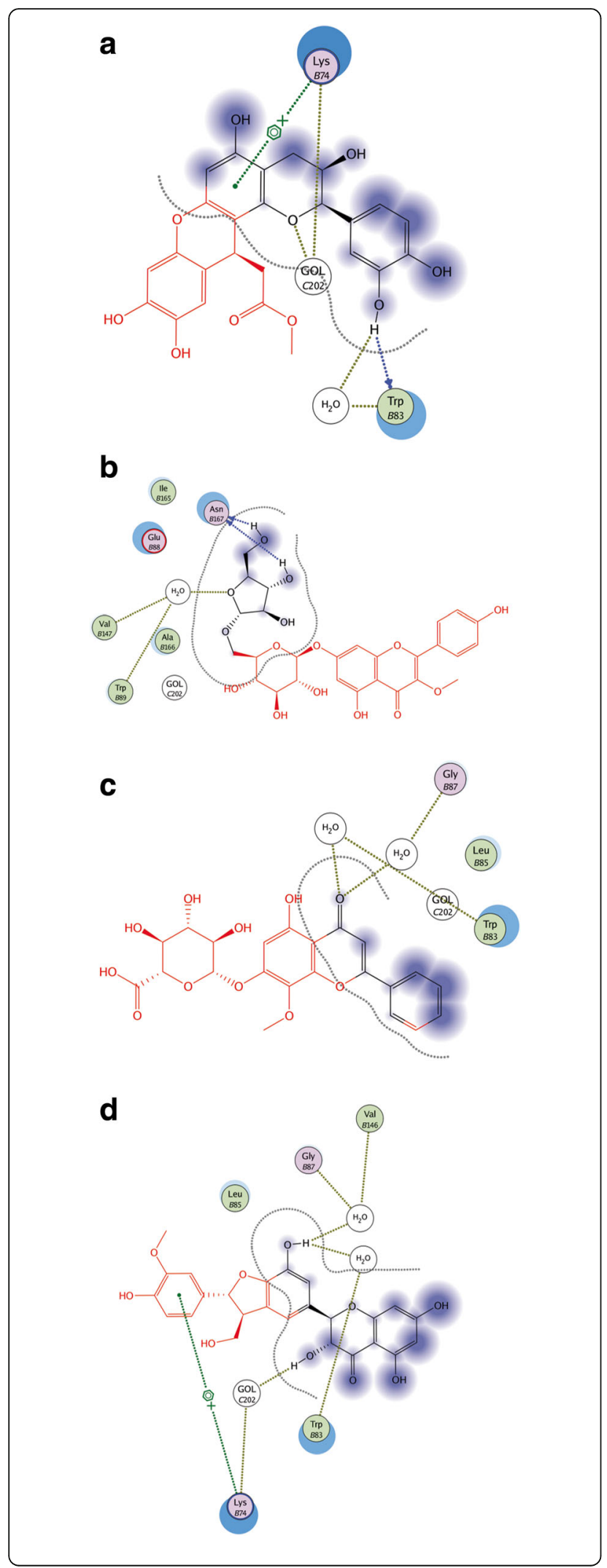

Fig. $62 \mathrm{D}$ interaction diagram; showing the interacting ligand atoms with specific residues in receptor protein. Dotted lines are showing specific interaction. a. Flavonoid No.7 b. Flavonoid No. 8 c. Flavonoid No. 9 d. Flavonoid No. 10

and the value of $\log \mathrm{P}$ Correlation Co-efficient obtained are shown below

$$
\begin{aligned}
& \text { Activity field }=\log \mathrm{P}(\mathrm{o} / \mathrm{w}), \text { Descriptor }=\mathrm{S} \log \mathrm{P}, \\
& \mathrm{PLS}=\mathrm{RMSE}=0.24071, \mathrm{R} 2=0.97662 \\
& \log \mathrm{P} \text { Correlation Coeffient }=+0.77652 \\
& \text { Normalization }=+0.95672
\end{aligned}
$$

Accordingly partial least square (PLS) experiment was performed to achieve three dimensional-QSAR (Fig. 9). Leave one out statistical procedure was used to get ideal number of components. It was done to build a regression model that is statistically significant. Crossvalidated coefficient $\mathrm{q} 2$ was used to measure the model quality. Conventional correlation coefficient r2 was utilized to obtain the external predictivity.

\section{Discussion}

Dengue is a mosquito-borne viral hemorrhagic illness that is very dangerous to human wellbeing in tropical and subtropical areas. The virus-encoded protease activity, important for dengue virus infection, requires two viral proteins, NS2B and NS3 [24]. It has been already established that the disruption of NS2B-NS3 protein complex has negative effect on viral replication [25]. In the present investigation, plant flavonoids have been tested as potential inhibitor of NS2B-NS3 complex of viral protease. Previously, Plant flavonoids were known for anti-inflammatory, anticancer and antiviral activities $[12,14]$. In present work we used structure based computational docking analysis tool to find the anti-dengue

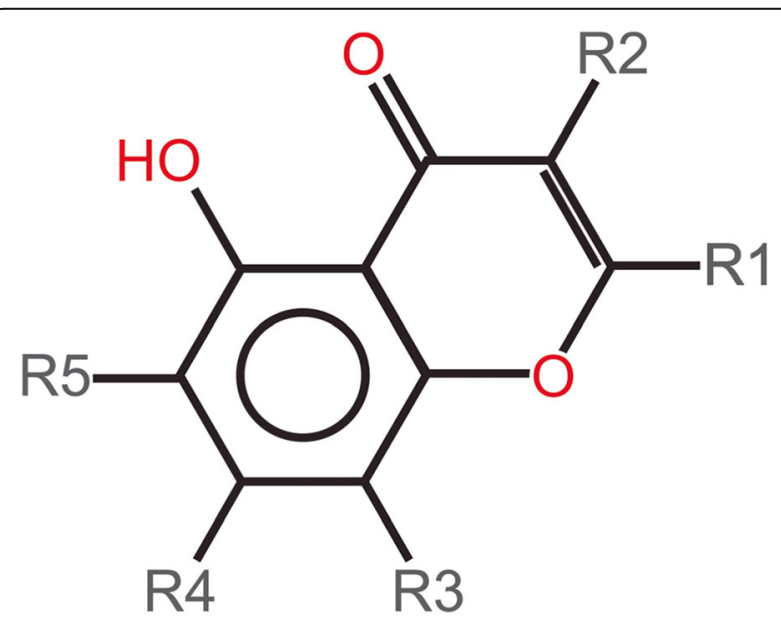

Fig. 7 Common Scaffolds obtained from Structure Activity Report; a. Scaffold 1 common in sevenall flavonoid structures 

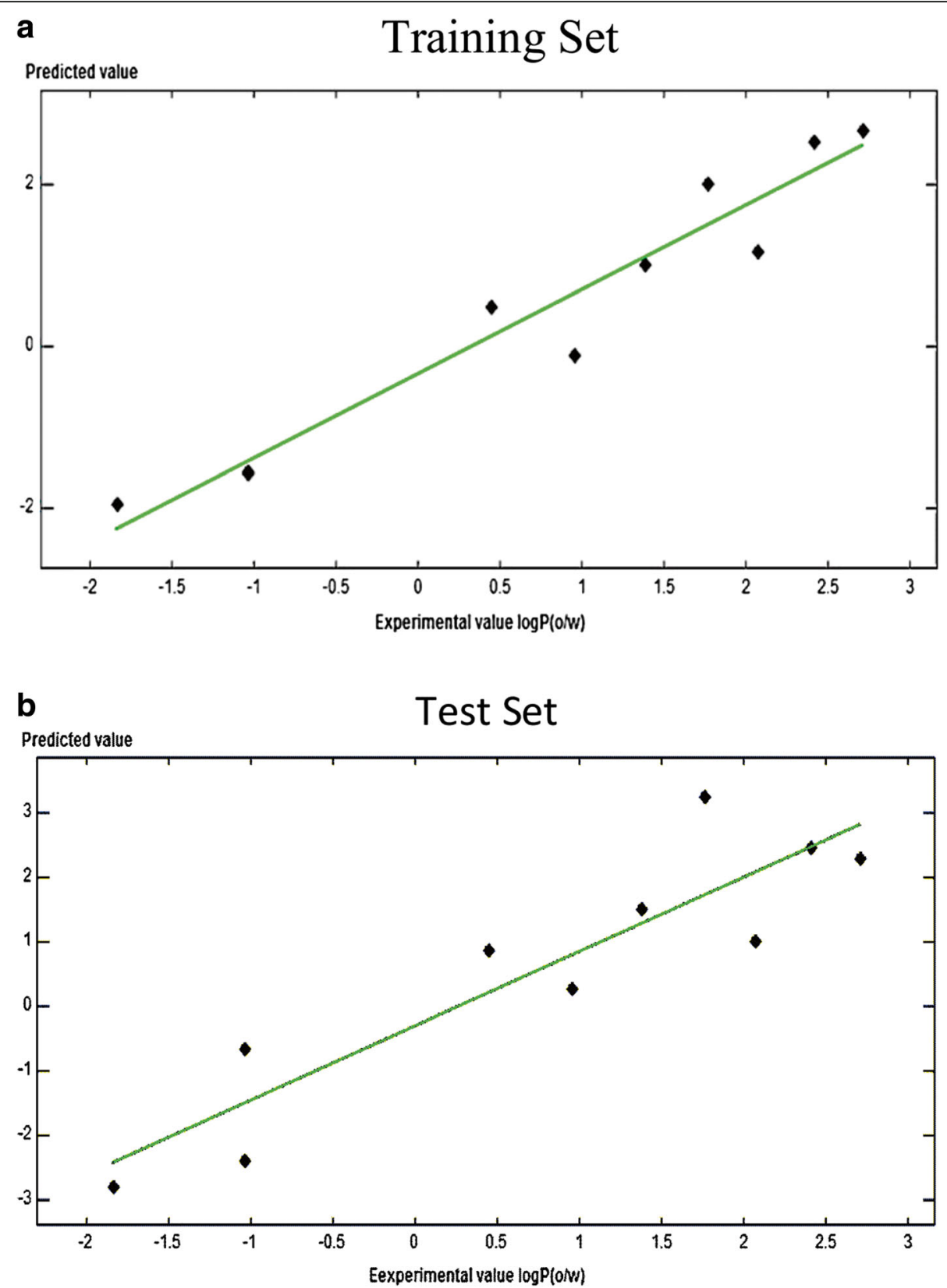

Fig. 8 QSAR model; a. Training set b. Test set

potential of flavonoids. More than 100 flavonoid structures were downloaded from chemebi. Docking of all flavonoid structures was done against the active site of dengue NS2B-NS3 protein. Docking analysis provided various designs that were scored to decide ideal restricting modes. We found very high scores of docking than previously reported data [26]. Docking analysis contributed towards basic idea and binding energy values for each ligand. After this, ligand interaction studies were done for the further confirmation of docking results and to have an insight into each interaction of atoms of ligand and protein. In our study we found more than one flavonoid as potential inhibitor of dengue NS2BNS3 so it was necessary to find out the common structure among all those flavonoids that showed high binding score. As the compounds that have common or correlated structures have similar physicochemical properties and thus have similar binding modes and subsequently comparable biological activities. To find out a common structural feature among flavonoids, structure activity report was generated and a common conformation was obtained. We are reporting this conformation 


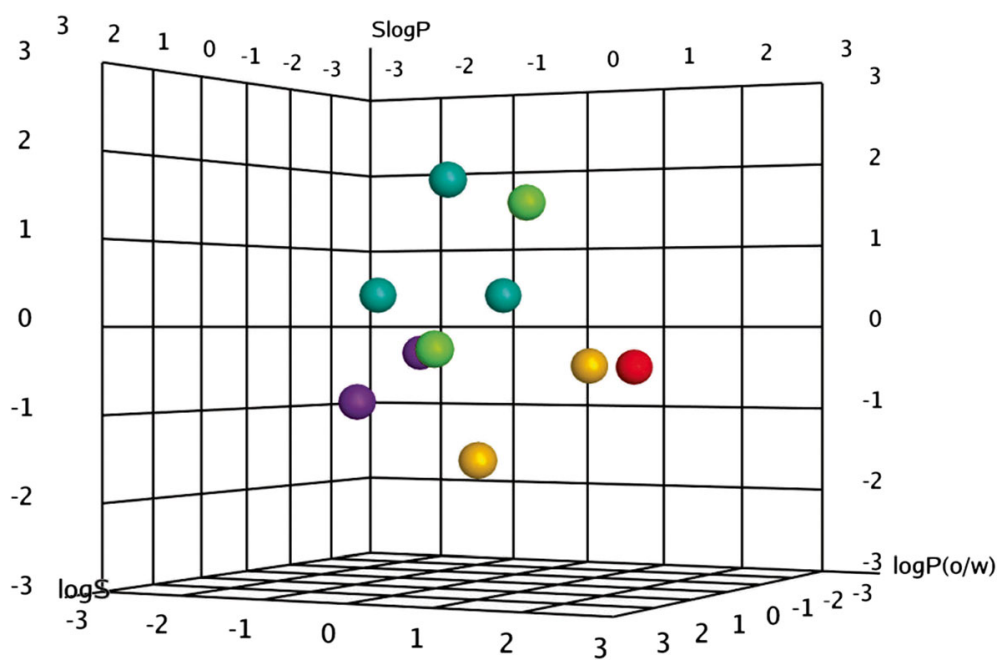

Fig. 9 3D Correlation Plot for the activities of QSAR; X-axis $\log P(O / W)$, Y-axis SlogP, Z-axis logS

for very first time and it is an important step towards development of novel drugs against dengue virus. Quantitative structure activity relationships (QSAR) have been used for the development of relationships between physicochemical properties of compounds and their biological activities to get a statistical model, which prove their binding assays. The basic principle involved in this process is that the difference in the structure of chemical compounds is accountable for the variation in their biological activities [27]. In the present study the value of correlation obtained from QSAR model showed that there is linear relationship between selected calculated descriptor values and activities of compounds. We are reporting ten naturally occurring flavonoids as potential inhibitors of dengue NS2B-NS3 protein complex, which can inhibit viral replication. These flavonoids were not known previously for their anti-dengue activity.

\section{Conclusions}

In present work, different plant flavonoids were docked and structure based SAR and QSAR analysis was done for dengue NS2B-NS3 protein. The results of statistical analysis of both models i.e., SAR and QSAR were convincing and comparable. The generated model was used to predict the effect of important structural characteristics of the potent inhibitor. The generated 3D-QSAR models were further verified by the docking studies of most potent and least active inhibitors so can be used for better drug development.

This study is an effort to explore novel inhibitors of dengue NS2B-NS3 and to through light on the structural and inhibitory activity of plant flavonoids. Consequently, ten flavonoids were found as inhibitors of NS2B-NS3. Henceforth, QSAR and SAR data provided in this study will serve as basis for a better drug development.

\section{Abbreviations}

a_acc: Number of hydrogen bond acceptor atoms; apol: Sum of the atomic polarizabilities; Asp: Aspartic acid; b rotN: Number of rotatable bond; Chi1: Atomic connectivity index; DENV: Dengue virus; E_ele: Electrostatic component of the potential energy; $E_{-} n b$ : Value of the potential energy with all bonded term disabled; His: Histidine; Log P: Partition coefficient; MOE: Molecular operating environment; NS2B: Non structural protein 2B; NS3: Non structural protein 3; OPLS-AA: Optimized potentials for liquid simulations for amino acids; PLS: Partial least square analysis; Q_pc+: Total positive partial charge; QSAR: Quantitative structure activity relationship; R2: Conventional correlation coefficient; RMSE: Root mean square error; SAR: Structure activity relationship; Ser: Serine; SlogP: Log of the octanol/ water partition coefficient; vsurf_g: Surface globularity;

vsurf_wpu: Hydrophilic volume

\section{Acknowledgements}

We acknowledge all members of virology lab for their help and support for this work.

\section{Funding}

This work was funded by the IFS Research Grant No. C/5260-1 to Dr. Muhammad Mubin and IFS Research grant No. C/5434-1 to Dr. Muhammad Shah Nawaz ul Rehman. Funding bodies have no role in the design of the study and collection, analysis, and interpretation of data and in writing this manuscript.

\section{Availability of data and materials}

The datasets used and/or analyzed during the current study available from the corresponding author on reasonable request.

\section{Authors' contributions}

MM and MSN conceived the idea and designed the experiments. MWS and AR did all experiments. MM, SMRD and MAAQ analyze and interpret the data. $M M, M A A Q, S M R D$ and MSN wrote and critically reviewed the manuscript. All authors have read and approved the manuscript.

\section{Ethics approval and consent to participate} N/A

\section{Competing interests}

The authors declare that they have no competing interests.

\section{Publisher's Note}

Springer Nature remains neutral with regard to jurisdictional claims in published maps and institutional affiliations. 


\section{Author details}

${ }^{1}$ Virology Lab, Centre of Agricultural Biochemistry and Biotechnology, University of Agriculture, Jail road, Faisalabad 38000, Pakistan. ${ }^{2}$ Department of Infection and Immunity, Research Center, King Faisal Specialist Hospital and Research Center, Riyadh, Saudi Arabia. ${ }^{3}$ Department of Microbiology and Immunology, College of Medicine, Alfaisal University, Riyadh, Saudi Arabia. ${ }^{4}$ Liver Disease Research Center, King Saud University, Riyadh, Saudi Arabia. ${ }^{5}$ Department of Theriogenology, Faculty of Veterinary and Animal Sciences, Gomal University, Dera Ismail Khan, Pakistan.

Received: 10 July 2017 Accepted: 11 April 2018

Published online: 19 April 2018

\section{References}

1. Gubler DJ. Dengue and dengue hemorrhagic fever. Clin Microbiol Rev. 1998;11(3):480-96

2. Chambers TJ, Hahn CS, Galler R, Rice CM. Flavivirus genome organization, expression, and replication. Ann Rev Microbiol. 1990;44:649-88.

3. Falgout B, Pethel M, Zhang YM, Lai CJ. Both nonstructural proteins NS2B and NS3 are required for the proteolytic processing of dengue virus nonstructural proteins. J Virol. 1991;65(5):2467-75.

4. Yang CC, Hsieh YC, Lee SJ, Wu SH, Liao CL, Tsao CH, Chao YS, Chern JH, Wu $C P$, Yueh A. Novel dengue virus-specific NS2B/NS3 protease inhibitor, BP2109, discovered by a high-throughput screening assay. Antimicrob Agents Chemother. 2011;55(1):229-38.

5. Lescar J, Luo D, Xu T, Sampath A, Lim SP, Canard B, Vasudevan SG. Towards the design of antiviral inhibitors against flaviviruses: the case for the multifunctional NS3 protein from dengue virus as a target. Antivir Res. 2008; 80(2):94-101.

6. Geiss BJ, Stahla H, Hannah AM, Gari AM, Keenan SM. Focus on flaviviruses: current and future drug targets. Future Med Chem. 2009;1(2):327-44.

7. Rothan HA, Abdulrahman AY, Sasikumer PG, Othman S, Rahman NA, Yusof R. Protegrin-1 inhibits dengue NS2B-NS3 serine protease and viral replication in MK2 cells. J Biomed Biotechnol. 2012;2012:251482.

8. Rothan HA, Han HC, Ramasamy TS, Othman S, Rahman NA, Yusof R. Inhibition of dengue NS2B-NS3 protease and viral replication in Vero cells by recombinant retrocyclin-1. BMC Infect Dis. 2012;12:314.

9. Cragg GM, Grothaus PG, Newman DJ. Impact of natural products on developing new anti-cancer agents. Chem Rev. 2009:109(7):3012-43.

10. Beecher GR. Overview of dietary flavonoids: nomenclature, occurrence and intake. J Nutri. 2003;133(10):3248S-54S.

11. Giovannini C, Filesi C, D'Archivio M, Scazzocchio B, Santangelo C, Masella R. Polyphenols and endogenous antioxidant defences: effects on glutathione and glutathione related enzymes. Ann Ist Super Sanita. 2006;42(3):336-47.

12. Sang S, Hou Z, Lambert JD, Yang CS. Redox properties of tea polyphenols and related biological activities. Antioxid Redox Signal. 2005;7(11-12):1704-14.

13. Friedman M. Overview of antibacterial, antitoxin, antiviral, and antifungal activities of tea flavonoids and teas. Mol Nutri Food Res. 2007:51(1):116-34.

14. Li Y, Fang H, Xu W. Recent advance in the research of flavonoids as anticancer agents. Mini-Rev Med Chem. 2007:7(7):663-78.

15. Fresco P, Borges F, Diniz C, Marques MP. New insights on the anticancer properties of dietary polyphenols. Med Res Rev. 2006;26(6):747-66.

16. Oak MH, El Bedoui J, Schini-Kerth VB. Antiangiogenic properties of natural polyphenols from red wine and green tea. J Nutri Biochem. 2005;16(1):1-8.

17. Middleton E Jr. Effect of plant flavonoids on immune and inflammatory cell function. Adv Exp Med Biol. 1998;439:175-82.

18. Lu Y, Yeap FL. The polyphenol constituents of grape pomace. Food Chem. 1999;65(1):1-8

19. Su BH, Shen MY, Esposito EX, Hopfinger AJ, Tseng YJ. In silico binary classification QSAR models based on 4D-fingerprints and MOE descriptors for prediction of hERG blockage. J Chem Inf Model. 2010;50(7):1304-18.

20. Erbel P, Schiering N, D'Arcy A, Renatus M, Kroemer M, Lim SP, Yin Z, Keller $\mathrm{TH}$, Vasudevan SG, Hommel U. Structural basis for the activation of flaviviral NS3 proteases from dengue and West Nile virus. Nat Struct Mol Biol. 2006; 13(4):372-3.

21. Sarwar MW, Saleem IB, Ali A, Abbas F. Insilico characterization and homology modeling of Arabitol dehydrogenase (ArDH) from Candida albican. Bioinformation. 2013;9(19):952-7.

22. Wright JS, Anderson JM, Shadnia H, Durst T, Katzenellenbogen JA. Experimental versus predicted affinities for ligand binding to estrogen receptor: iterative selection and rescoring of docked poses systematically improves the correlation. J Comput Aided Mol Des. 2013;27(8):707-21.

23. Santos CB, Vieira JB, Lobato CC, Hage-Melim LI, Souto RN, Lima CS, Costa EV, Brasil DS, Macedo WJ, Carvalho JC. A SAR and QSAR study of new artemisinin compounds with antimalarial activity. Molecules. 2013;19(1):367-99.

24. Noble CG, Seh CC, Chao AT, Shi PY. Ligand-bound structures of the dengue virus protease reveal the active conformation. J Virol. 2012;86(1):438-46.

25. Robin G, Chappell K, Stoermer MJ, Hu SH, Young PR, Fairlie DP, Martin JL. Structure of West Nile virus NS3 protease: ligand stabilization of the catalytic conformation. J Mol Biol. 2009;385(5):1568-77.

26. Qamar TU, Mumtaz A, Ashfaq UA, Azhar S, Fatima T, Hassan M, Hussain SS, Akram W, Idrees S. Computer aided screening of phytochemicals from Garcinia against the dengue NS2B/NS3 protease. Bioinformation. 2014;10(3):115-8.

27. Verma J, Khedkar VM, Coutinho EC. 3D-QSAR in drug design-a review. Curr Top Med Chem. 2010;10(1):95-115.

\section{Ready to submit your research? Choose BMC and benefit from:}

- fast, convenient online submission

- thorough peer review by experienced researchers in your field

- rapid publication on acceptance

- support for research data, including large and complex data types

- gold Open Access which fosters wider collaboration and increased citations

- maximum visibility for your research: over $100 \mathrm{M}$ website views per year

At BMC, research is always in progress.

Learn more biomedcentral.com/submissions 